\title{
Avaliação da piscicultura na microrregião do Alto Pantanal - Mato Grosso, Brasil
}

\author{
Assessment of fish farming in the Microregion of upper Pantanal - Mato Grosso, Brazil
}

\author{
L. R. V. Curvo ${ }^{1 *}$; M. W. Ferreira ${ }^{2}$; G. E. O. Porfirio ${ }^{3}$; M. A. C. Oliveira ${ }^{2}$; S. B. A. \\ de Alencar'; C. S. Costa ${ }^{4}$; G. B. de Andrade ${ }^{2}$ \\ ${ }^{1}$ Instituto Federal de Educação, Ciência e Tecnologia de Mato Grosso (IFMT), 78.005-200, Centro Norte, Cuiabá- \\ MT, Brasil. \\ ${ }^{2}$ Universidade Católica Dom Bosco (UCDB), Programa de Pós-graduação em Ciências Ambientais e \\ Sustentabilidade Agropecuária, 79117-010, Jardim Seminário, Campo Grande-MS, Brasil. \\ ${ }^{3}$ Programa de Pós-graduação em Recursos Naturais, Universidade Federal de Mato Grosso do Sul, 79070-900, \\ Campo Grande-MS, Brasil. \\ ${ }^{4}$ Instituto Federal de Educação, Ciência e Tecnologia de Mato Grosso do Sul (IFMS), 79907-414, \\ Ponta Porã-MS, Brasil.
}

*lucimar.curvo@cba.ifmt.edu.br

(Recebido em 07 de agosto de 2019, aceito em 13 de janeiro de 2020)

\begin{abstract}
A piscicultura surge como modalidade de aquicultura alternativa, a qual vem se expandindo nos últimos anos. O estado de Mato Grosso (Brasil) vem se situando como o quarto maior produtor de peixes do Brasil, atingindo uma produção de 54.510 toneladas em 2018. Objetivou-se nesta pesquisa avaliar a piscicultura na Microrregião do Alto Pantanal. Foi adotada uma abordagem quali-quantitativa descritiva a partir de material documental, de dados fornecidos pelo Instituto de Defesa Agropecuária de Mato Grosso (INDEA/MT) referentes aos anos de 2016 e 2017. Analisou-se estatisticamente através do software R Studio ${ }^{\circledR}$ os principais compradores, vendedores e produtores por município e evidenciou-se que Cáceres e Poconé são os maiores produtores e vendedores dessa microrregião. Nossa Senhora do Livramento e Vila Bela de Santíssima Trindade são os maiores compradores. Constatou-se que os municípios de Cáceres e Poconé abastecem principalmente o mercado interno e o estado. Identificou-se necessidades de estudos em toda a cadeia produtiva, de modo a destacar as demandas do setor, tais como a comercialização, produção, sanidade e os aspectos socioambientais. Da mesma forma, evidenciou-se a importância do aumento da fiscalização e inclusão de políticas públicas que venham ao encontro das demandas dos produtores e/ou envolvidos na atividade de piscicultura nessa área do Pantanal. Dessa forma, tornar-se-iam viáveis contribuições para a sustentabilidade agropecuária, gerando riquezas, distribuição de renda, criação de postos de trabalho, participação comunitária intersetorial, empoderamento, justiça e equidade socioambiental.

Palavras-chave: pantanal norte, aquicultura, arranjo produtivo local.
\end{abstract}

Fish farming emerges as an alternative mode of aquaculture, which has been expanding in recent years. The state of Mato Grosso (Brazil) has originated as the largest fish producer in Brazil, reaching a production of 54,510 tons in 2018 The objective of this research was to evaluate fish farming in the Upper Pantanal Microregion. A descriptive qualitative and quantitative approach was adopted based on documentary material, data provided by the Institute of Agricultural Defense of Mato Grosso (INDEA / MT) for the years 2016 and 2017. The main buyers were statistically analyzed using R Studio software, sellers and producers by municipality. Cáceres and Poconé are the largest producers and sellers of this Microregion. Nossa Senhora do Livramento and Vila Bela de Santissima Trindade are the largest buyers. The analysis also showed that the municipalities of Cáceres and Poconé supply mainly the domestic market and the state. Needs for studies throughout the production chain were identified, in order to detach the demands of the sector, such as marketing, production, health, and social and environmental aspects. Likewise, it was highlighted the importance of increasing the supervision and inclusion of public policies that meet the demands of producers and / or those involved in fish farming in this region of the Pantanal. Thus, contributions to agricultural sustainability would become viable, generating wealth, income distribution, job creation, intersectoral community participation, empowerment, justice and socio-environmental equity. Keywords: Northern Pantanal, Aquiculture, local productive arrangement. 


\section{INTRODUÇÃO}

Os processos de inovação tecnológica têm exercido grande influência nos avanços observados no setor do agronegócio local e mundial. Esses avanços são resultantes de estudos científicos voltados principalmente para o melhoramento genético, segurança biológica, mecanização, automação, precisão, irrigação, monitoramento, manejo e gestão das atividades humanas [1].

Segundo a Organização das Nações Unidas para a Agricultura e Alimentação (FAO), o setor primário mundial da pesca de captura (profissional) envolveu 59,6 milhões de pessoas na pesca de captura e aquicultura em 2016 - desses 19,3 milhões em aquicultura e 40,3 milhões na pesca de captura [2]. Esse mesmo relatório demostra que o consumo de peixe per capita na alimentação humana passou de 9,0 $\mathrm{kg}$ em 1961 para 20,2 $\mathrm{kg}$ em 2015, a uma taxa média de crescimento de $1,5 \%$ ao ano [2].

Analisando o cenário da aquicultura brasileira, observa-se que no ano de 2015 a atividade atingiu um valor de produção de $\mathrm{R} \$ 4,39$ bilhões de reais, com a maior parte $(69,9 \%)$ oriunda da criação de peixes [3]. No Brasil, a produção de peixes visando à alimentação humana vem acompanhando o cenário mundial no que tange ao aumento de produção, sendo prevista uma alta de $104 \%$ até 2025 [2].

Entre 2005 e 2017 novas empresas foram estabelecidas e a rápida profissionalização e a intensificação tecnológica aumentaram a produção da piscicultura brasileira em 268,8 \%, passando de 257 mil para 691 mil toneladas de pescado nesse período [4]. Nesse mesmo aspecto, a produção de peixes em cativeiro no Brasil vem aumentando, principalmente devido às políticas públicas de incentivos governamentais [3,5]. Esse crescimento fez com que a indústria de peixes do Brasil, como atividade do agronegócio, ganhasse mais importância na economia local, regional e mundial, devido ao aumento das demandas do comércio exterior [6]. Ainda, esse crescimento é relevante no cenário do agronegócio brasileiro uma vez que os produtores, além de investirem nas culturas de soja e milho, pecuária leiteira e de corte, podem ampliar o portfólio de produtos ao incluir a piscicultura, aumentando, dessa forma, a produtividade e rentabilidade de suas propriedades $[7,8]$.

Corroborando com esse desenvolvimento da piscicultura brasileira, o estado do Mato Grosso, com ênfase na Microrregião do Alto Pantanal, mostra-se como uma área de crescente interesse econômico para as atividades aquícolas. Apresentando uma área de $136.928 \mathrm{~km}^{2}$, o Pantanal abrange, ainda, a maior área alagável do planeta, com um complexo sistema hidrológico, composto de pulsos de inundações sazonais influenciados pela precipitação e fatores do relevo $[9,10,11,12]$.

Com importância socioambiental e econômica, a Microrregião do Alto Pantanal [13], uma vez que demonstra ser um ambiente frágil, susceptível a danos ambientais ocasionados por ações antrópicas $[14,15,16]$, por interesses políticos e sociais em nível local, regional, nacional e mundial, e que estas deveriam ir de encontro às demandas de desenvolvimento sustentável [17, 61]. Entende-se que o estudo e caracterização da piscicultura da Microrregião Alto Pantanal, com foco na sua comercialização e produção seja de enorme relevância em todas as por se configurar como área de interesse econômico devido à diversidade de seus serviços ambientais, científico e ecológico no Pantanal Norte de Mato Grosso [18]. É uma região de grande interesse [19, 20], pois se configura como uma das maiores reservas da biodiversidade mundial e em contrapartida sofre com a pressão antrópicas relacionadas ao agronegócio, principalmente pecuária e agricultura extensiva [21]. Ademais, destaca-se a relevância de se conhecer a região, em razão de seu destaque no cenário nacional e mundial, sendo considerada atualmente como patrimônio da humanidade e Reserva da Biosfera declarado em 2000 pela Organização das Nações Unidas para Educação, Ciência e Cultura - UNESCO [22]. É uma importante área úmida mundial e a maior planície sedimentar do planeta [11]. Abrange, ainda, a maior área alagável do planeta, com complexo sistema hidrológico, possuindo pulsos de inundações sazonais influenciados pela precipitação e fatores do relevo [12]. Esses e outros fatores motivaram a escolha dessa região como área de estudo para desenvolvimento da presente análise.

Acredita-se que de forma planejada, com políticas públicas adequadas e envolvimento social local, seja possível minimizar prováveis implicações futuras nos sistemas ecológicos naturais. 
Além disso, o estudo é importante para melhorar a compreensão e planejamento das atividades piscícolas na Microrregião do Alto Pantanal, com o objetivo maior de contribuir para a sustentabilidade produtiva e conservação do bioma [24]. Assim, objetivou-se caracterizar e avaliar a atividade de piscicultura na Microrregião do Alto Pantanal (Pantanal Norte Matogrossense), dando ênfase na mensuração e avaliação de aspectos relativos à produção e comercialização de peixes em cativeiro na região.

\section{MATERIAL E MÉTODOS}

\section{1 Área de estudo}

O estudo foi realizado a partir de dados da Microrregião do Alto Pantanal (Figura 1), situada no estado do Mato Grosso. A população da região foi estimada em 160.515 pessoas [25, 26, 27 , 28] e está dividida em quatro municípios: Cáceres, Poconé, Curvelândia e Barão de Melgaço. A Microrregião possui uma área total de 53.590,469 km² [25, 26, 27, 28]. Localiza-se em uma região pantaneira que em sua maior parte é alagável durante o período de cheias, que ocorre entre os meses de janeiro e março [31].

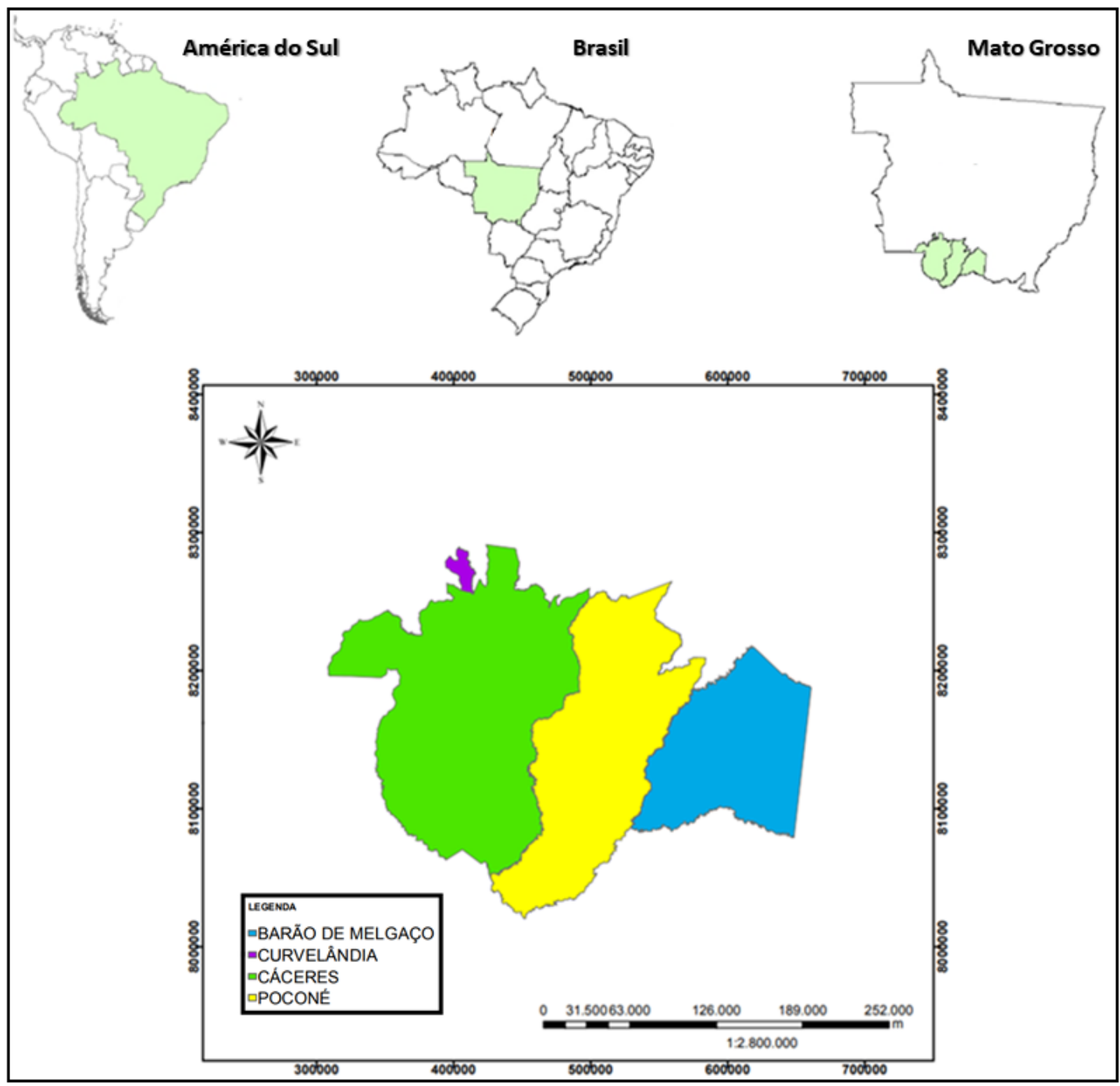

Figura 1: Mapa de localização da Microrregião do Alto Pantanal no estado do Mato Grosso, Brasil. Elaboração: Agnelo Vedana. 


\subsection{Obtenção e análise de dados secundários quantitativos}

Para caracterizar e avaliar a piscicultura da microrregião do Alto Pantanal adotou-se uma abordagem quali-quantitativa descritiva, por meio da análise de dados secundários [33, 34, 35].

Os dados utilizados neste estudo foram obtidos a partir das seguintes fontes: (i) Cadastro Atualizado de Piscicultores, Guias de Transporte Animal (GTA) e Relatório de Despesca realizadas na Microrregião do Alto Pantanal fornecidos pelo Instituto de Defesa Agropecuária de Mato Grosso (INDEA/MT), referentes aos anos de 2016 e 2017 [62], que foram usados para a análise visando avaliar a prática da piscicultura; e (ii) Anuários estatísticos e sites oficiais de órgãos do Governo Federal e internacional, como: Ministério da Agricultura, Pecuária e Abastecimento (MAPA), Instituto Brasileiro de Geografia e Estatística (IBGE), Organização das Nações Unidas para a Agricultura e Alimentação (FAO), entidades não-governamentais: Associação Nacional de Aquicultura (PEIXE BR), Federação da Agricultura e Pecuária do Estado do Mato Grosso (FAMATO), Instituto Mato-Grossense de Economia Agropecuária (IMEA) e Instituto de Pesquisa Aplicada (IPEA), com o intuito de complementar e discutir os resultados.

Por sua vez, os dados obtidos foram organizados e tabulados em planilhas no Software Excel 2013 (Microsoft Office ${ }^{\circledR}$ ). Utilizou-se como instrumento metodológico para a obtenção de informações os dados secundários como sendo "aqueles que já foram coletados, tabulados, ordenados e, às vezes, até analisados e que estão catalogados à disposição dos interessados [36]. As fontes básicas são a própria empresa, governos, instituições não governamentais e serviços padronizados de informações" [36]. Assim sendo, os dados secundários desta pesquisa foram fornecidos pelo Instituto de Defesa Agropecuária de Mato Grosso (INDEA/MT) com relação à quantidade de viveiros, lâmina d'água e produção por munícipio (Barão de Melgaço, Cáceres, Curvelândia e Poconé). A análise dos dados efetivou-se por intermédio de estatística descritiva, obtendo-se as médias e os desvios padrões.

Os principais compradores e vendedores e a origem do pescado comprado foram identificados por meio do percentual de compras e compradores obtidos por meio da análise das Guias de Transporte Animal (GTAs), Relatório de Despesca e Cadastro Atualizado de Piscicultores, onde a comparação das populações foi realizada por meio do teste de Kruskal-Wallis, com o auxílio do pacote Agricolae [37], a 5\% de probabilidade Todas as análises estatísticas foram realizadas no software R [38], com o auxílio do pacote Plotly [39], igualmente realizadas no software R Studio.

\section{RESULTADOS E DISCUSSÃO}

\subsection{Tipos de peixes criados na Microrregião do Alto Pantanal}

A FAO (2018) [23] publicou recentemente relatório sobre o estado da pesca e aquicultura mundial e mencionou que são exploradas comercialmente 548 espécies de organismos, sendo que entre os peixes as carpas capim (Ctenopharyngodon idellus) e a prateada (Hypophthalmichthys molitrix) tiveram a maior produção em 2016, representando $21 \%$ da produção mundial. No Brasil, a produção atingiu a marca de $722.560 \mathrm{t}$, representando um aumento de 4,5\% em relação ao ano de 2017.

Dos peixes criados em cativeiro pela piscicultura brasileira em 2018, predominou a tilápia, atingindo 400.280 (t) no ano de 2018, tendo um acréscimo na produção de $11,9 \%$ em relação a 2017. Os maiores estados produtores de tilápia são: Paraná (123.000 t), São Paulo (69.500), Santa Catarina (33.800), Minas Gerais (31.500) e Bahia (24.600 t). O estado de Mato Grosso possu cadastrado aproximadamente 10.218 estabelecimentos agropecuários na aquicultura [29].

Os tambaquis (Colossoma macropomum) possuem alto valor agregado, mas apresentam baixos índices zootécnicos, como crescimento, conversão alimentar, exigência nutricional, resistência a doenças e ao manejo, que comprometem a produção dessas espécies [40]. Outra espécie muito produzida na piscicultura brasileira é a tilápia em suas diversas variedades [29]. A criação de tilápia no Brasil teve seu início na década de 1970, introduzida pelo Departamento Nacional de Obras Contra as Secas (DNOCS) [41].

O maior número de estabelecimentos agropecuários em Mato Grosso se dedicou a criação de tambatinga, tambaqui, pacu e tambacu, seguidos de outros peixes (Figura 2) [29]. 


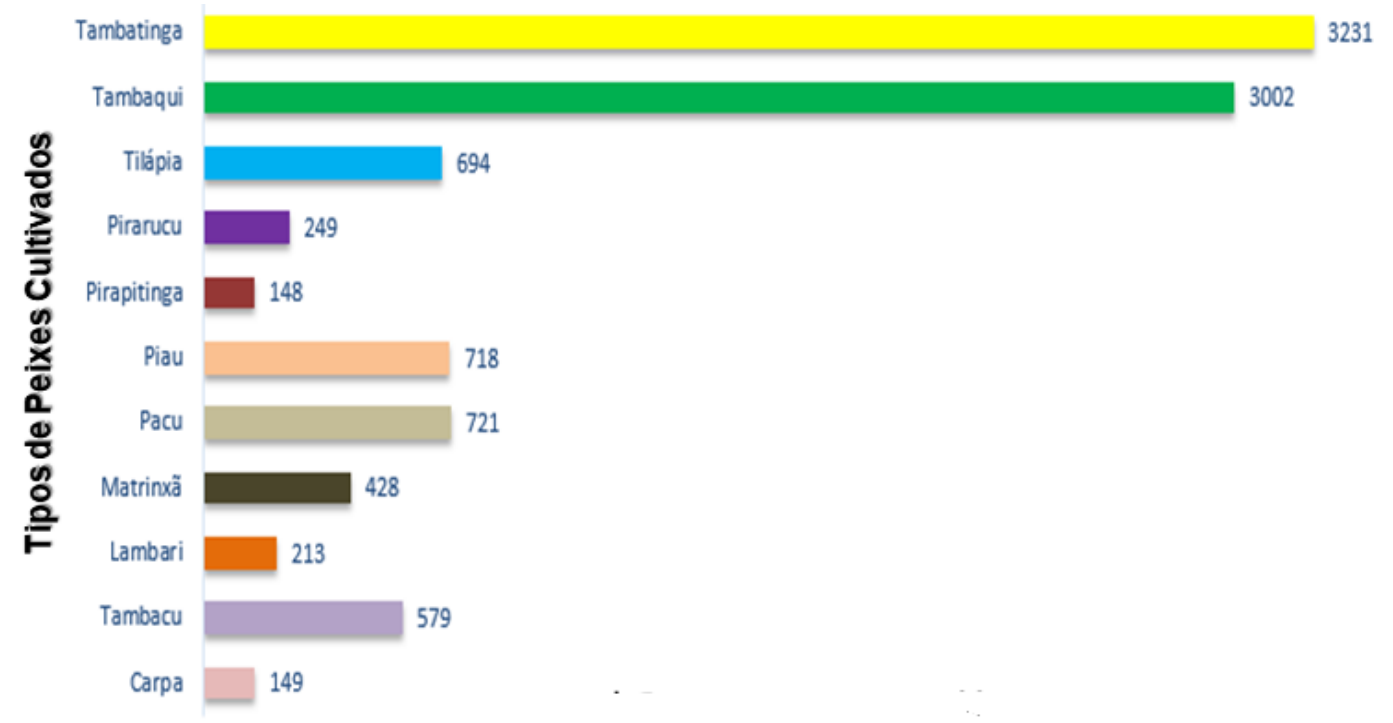

\section{Número de Estabelecimentos Agropecuários (Pisciculturas)}

Figura 2. Número de estabelecimentos agropecuários em Mato Grosso por tipos de peixes s criados. Fonte: Brasil (2017) [29].

Através de dados obtidos junto ao INDEA (Figura 3), referentes aos anos de 2016 e 2017, constatou-se neste estudo a existência de 131 viveiros escavados de pisciculturas em atividade na Microrregião do Alto Pantanal. Através da análise desses dados foi possível listar os principais peixes explorados comercialmente, a quantidade de viveiros e a sua ocorrência nos respectivos municípios. O peixe mais utilizado para criação foi a tambatinga [42], sendo encontrada em 34 criadouros, correspondendo a 25,95\% de ocorrência.

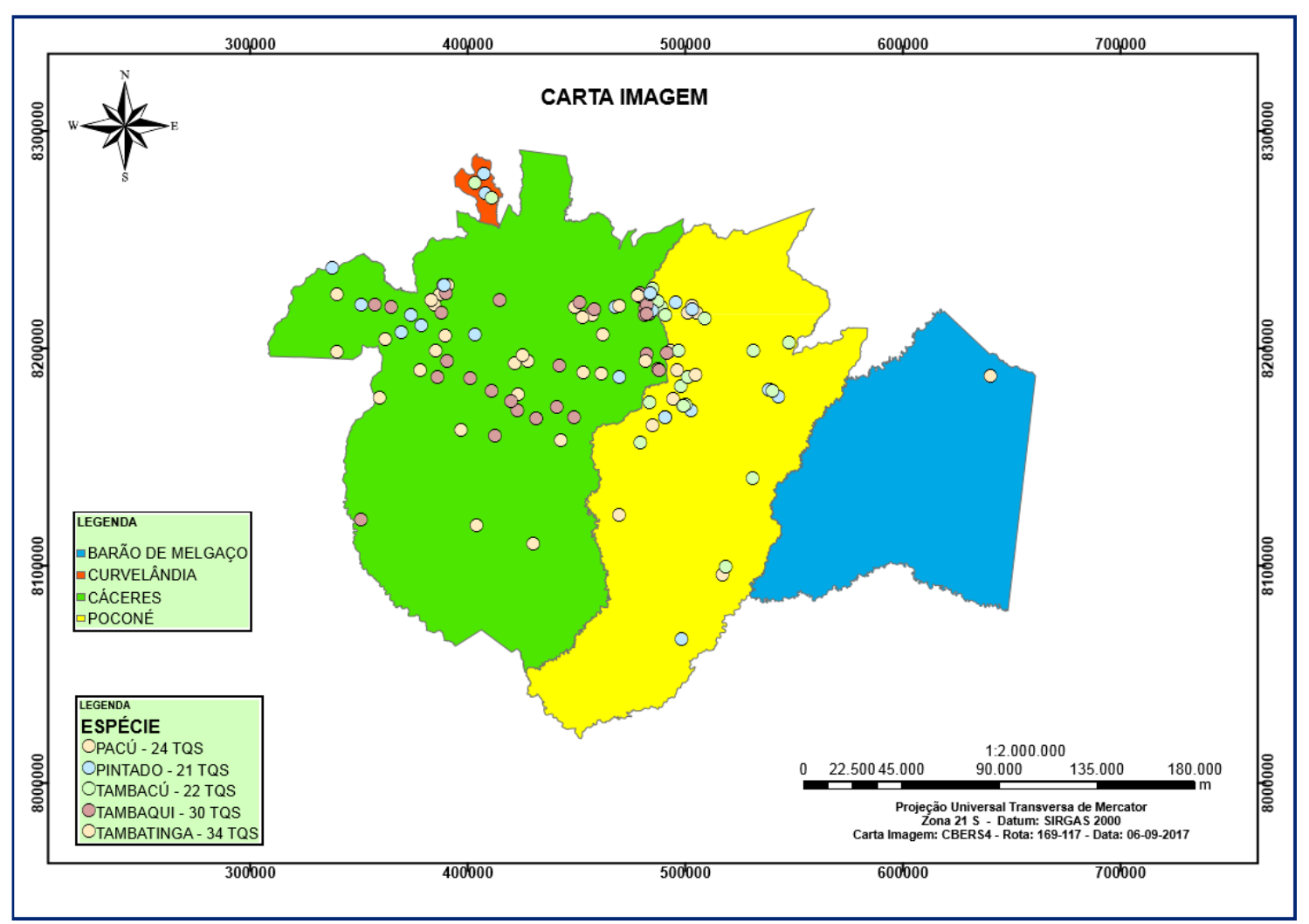

Figura 3 - Localização das pisciculturas e quantidade dos viveiros por tipos de peixes criados. Fonte: INDEA (2016-2017 [62]. Elaboração: Agnelo Vedana. 
A tambatinga é resultado do cruzamento interespecífico entre a fêmea do tambaqui (Colossoma macropomum) e o macho da pirapitinga (Piaractus brachypomus), duas espécies amazônicas, muito adaptadas à criação em cativeiro, com aceitação no mercado e que possuí ótimo desempenho produtivo [43]. É caracterizada como sendo um peixe redondo, com escamas, onívoro, de caráter oportunista, de grande porte, rusticidade e crescimento rápido [44]. Existem relatos de que essa espécie tem sido criada na região no estado de Tocantins com condições bem precárias, inclusive com escassez de água [45].

O peixe menos produzido, por sua vez, foi o pintado (Pseudoplatystoma sp.) encontrado em 21 estabelecimentos agropecuários (Figura 3), o que corresponderam a 16,15\% de ocorrência. Embora seja a carne mais apreciada do mercado, a criação do pintado de rio, em especial Pseudoplatistoma fasciatum, apresenta a particularidade fisiológica reprodutiva em cativeiro, por ser uma espécie nativa. Dessa maneira, compreende-se que seus ciclos de maturação são dependentes de fatores ambientais, como da precipitação, do volume e temperatura da água [46]. Essas dificuldades podem estar relacionadas à menor ocorrência do pintado e daqueles resultados de seu cruzamento interespecífico nas pisciculturas da Microrregião do Alto Pantanal, predominando a criação desses na microrregião Centro-Sul Mato-grossense, com percentuais correspondentes à $34 \%$ da produção total do estado cerca de $97 \%$ são representados por peixes não-nativos [23].

Os surubins e os outros peixes de cruzamentos interespecíficos se destacam como promissora para produção em cativeiro por apresentarem um manejo mais simples, resultando em menor custo de produção, já que possuem o crescimento rápido e melhor aceitação de alimento artificial [47, 48]. Os surubins, de um modo geral, estão entre os peixes comerciais com grande aceitação pelo consumidor no Brasil, tendo em vista o alto padrão de sua carne, ausência de espinhos intramusculares e seu grande porte $[49,50]$. Ainda sobre as espécies de surubins nativos de rios e outros peixes de cruzamentos de suas espécies. Os cruzamentos interespecíficos de espécies de Psudoplatystoma sp. (surubins) apresentaram maior percentagem de corpo, indicando maior potencial de rendimento de carcaça que as espécies nativas de rio.

Constatou-se que muitos produtores cadastraram no INDEA/MT a quantidade de viveiros em suas propriedades na mesma coordenada geográfica, ou seja, estas ao serem plotadas sobre o mapa (Figura 2) acarretam a sobreposição destes. Isso pode ser justificado pela escala do mapa elaborado (1:2.000.000). Além desse fato, por erros de GPS, muitas coordenadas que indicavam a localização dos viveiros nas propriedades cadastradas no INDEA apareciam no mapa fora dos limites de divisões dos quatro municípios estudados. Assim, consideraram-se na Figura 2, apenas os municípios que tinham coordenadas corretas e retiraram-se as sobreposições. Já na Tabela 1, considerou-se para cálculos estatísticos, todos os locais de criação de peixes em viveiros escavados que possuem o cadastro no INDEA/MT, independente das coordenadas geográficas e lou de estarem ou não em atividades (Inativos).

Após essas observações, considerando-se os viveiros da Figura 2 e sua distribuição espacial por tipos de peixes criados, constatou-se que tambatinga e tambacu são produzidos através do cruzamento interespecífico, e representaram 42,74\% das dos peixes criados na Microrregião. Já os nativos, ou seja, aqueles que são provenientes do cruzamento de matrizes que são retiradas dos rios, como o pacu, tambaqui e pintado somaram 57\% dessa produção (Figura 4). 


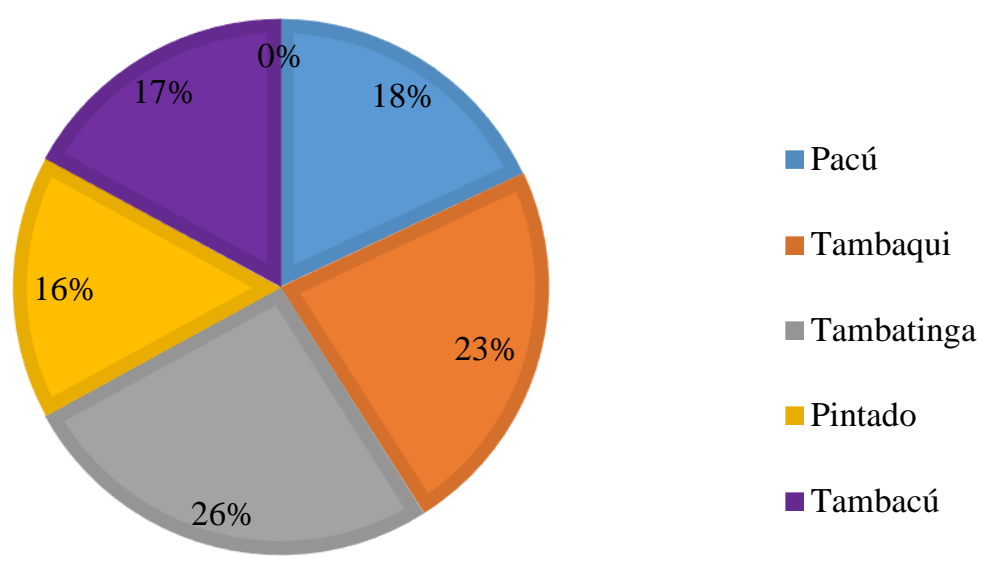

Figura 4 - Percentual de viveiros e tipos de peixes criados na Microrregião do Alto Pantanal. Elaboração: o autor. Fonte dos dados: BRASIL (2017) [29].

Os tipos de peixes mais comuns produzidas por região no Brasil são: i) tambaqui, pirarucu e pirapitinga na região Norte; ii) tilápia no Nordeste; iii) tambaqui e os de resultados de seus cruzamentos interespecíficos, o pacu e o pintado no Centro-Oeste; iv) tilápia, pacu e pintado no Sudeste; v) carpa, tilápia, jundiá, na Região Sul do Brasil [51].

Torna-se importante salientar que o abastecimento dos locais de criação ou dos reservatórios destinados a criação de peixes é um fator ambiental a ser discutido na Microrregião estudada. A maioria das formas de uso da água destinada à piscicultura em Mato Grosso são de nascentes e rios próximos aos viveiros [7]. A Região Centro-Sul de Mato Grosso, mais especificamente na região da Baixada Cuiabana, faz uso de água de chuva, sub-superficial e de afloração na superfície, visto que em outras regiões do estado a circulação da água é feita por gravidade, de um viveiro para o outro [7].

Nesse contexto, torna-se relevante também avaliar a questão referente à introdução de peixes exóticos e invasores em águas continentais brasileiras, visto que estas podem causar danos ambientais e encontram-se, intimamente, associadas à forma de abastecimento e aspectos sanitários [60]. A introdução de espécies exóticas nos ambientes naturais onde elas não ocorriam resultam de atividades antrópicas, podendo causar danos e afetar a biodiversidade, sendo, por vezes, consideradas como "poluentes biológicos" [52]. Assim sendo, os danos além de ambientais, podem ocasionar prejuízos às atividades econômicas, com danos à atividade pesqueira, riscos sanitários, gastos com manutenção de turbinas em hidroelétricas, entre outros.

A União Internacional da Conservação da Natureza (IUCN) considera uma espécie exótica aquela que se encontra fora de sua área de distribuição natural e que possui capacidade de se adaptar e reproduzir nessa nova área. Se a espécie exótica causar ameaças a outras espécies, aos ecossistemas e ao próprio homem, esta passa a ser uma espécie exótica invasora [53].

No Brasil, especialmente no Pantanal, a introdução de espécies exóticas nas bacias hidrográficas ocorreu de maneira acidental ou intencional [19, 20, 54], com interesse principalmente econômico (desportivo, ornamental, piscicultura, controle biológico, alimentação etc.). Existem vários exemplos de espécies introduzidas de forma intencional, assim como a tilápia (Tilapia rendali) no reservatório da Companhia Energética de São Paulo (CESP) em 1950, com o intuito de promover o povoamento [20].

Existem relatos da introdução do tucunaré - Cichla sp (Pisces, Cichlidae) no Pantanal [55]. O tucunaré foi acidental introduzido na bacia do Prata, Pantanal Sul, ocasionado pelo rompimento de uma represa na Fazenda Santo Antônio do Piquirí, na área rural de Corumbá/MS, na divisa dos estados de Mato Grosso e Mato Grosso do Sul, em 1982 [56, 57].

Identificou-se ainda que, presente na mesma característica de agrupamento zootécnico: o formato do corpo, o tambaqui e o pacu apresentaram expressiva produção na área de estudo, demonstrando um interesse comercial muito grande, sendo as espécies mais pescadas na região amazônica e mais criadas em cativeiro no Brasil $[1,58]$. O tucunaré é uma espécie que tem alta 
produtividade em cativeiro, aspecto justificado pela sua rusticidade, por ser onívoro, possuir um desempenho de crescimento rápido, fácil adaptação a cativeiro e alta aceitação de rações artificiais $[1,58]$.

Acredita-se que muitos estabelecimentos estão inativos na microrregião estudada e ainda, que possam não ter realizado despesca ou emitidos Guias de Transporte Animal (GTAs). Segundo dados evidenciados no Censo Agropecuário de 2017, os tipos de peixes mais criados nos estabelecimentos agropecuários nos municípios da Microrregião do Alto Pantanal em Cáceres, foram: carpa, tambacu, curimatã, jundiá, lambari, matrinxã, pacu, pintado, piau, Pirapitinga, pirarucu, surubim, truta, tilápia, tambaqui e tambatinga. As maiores produções de peixes em Mato Grosso ficam sempre concentradas no município de Sorriso/MT, na Microrregião Centro-Sul e Norte. Esses mesmos autores mencionam que em 2013, o município de Poconé constituía o $4^{\circ}$ maior produtor do estado [59].

\subsection{Avaliação da produção e comercialização de peixes de cativeiro na Microrregião do Alto Pantanal Mato-grossense}

Buscando caracterizar as pisciculturas com relação à quantidade de viveiros, lâmina d'água e produção por munícipio, nota-se que Poconé tem as maiores médias para as três variáveis analisadas, sendo seguido pelos municípios de Curvelândia e Cáceres. Ademais, constata-se que Barão de Melgaço apresentou as menores médias para as variáveis abordadas. Ressalta-se, ainda que o município de Poconé possui o maior número de viveiros, entre os demais municípios avaliados (Tabela 1).

Tabela 1. Estatística descritiva das variáveis analisadas quanto a caracterização da piscicultura na Microrregião do Alto Pantanal em função das cidades de Barão de Melgaço, Cáceres, Curvelândia e Poconé.

\begin{tabular}{cccccc}
\hline & Variável & Média & $\begin{array}{c}\text { Desvio } \\
\text { Padrão }\end{array}$ & Soma & Mediana \\
\hline BARÃO DE & & 3,00 & 4,76 & 12 & 1,0 \\
MELGAÇO & & 5,3 & 7,66 & 318 & 3,0 \\
CÁCERES & Quantidade de viveiros & 9,83 & 10,49 & 59 & 8,5 \\
CURVELÂNDIA & & 110,35 & 1036,6 & 10263 & 1,0 \\
POCONÉ & & 0,375 & 0,47 & 1,5 & 0,25 \\
\hline BARÃO DE & & 2,80 & 11,35 & 168,44 & 0,46 \\
MELGAÇO & & 3,06 & 3,57 & 18,4 & 1,5 \\
CÁCERES & Lâmina d'agua & 224,005 & 1426,2 & 20832,47 & 0,14 \\
CURVELÂNDIA & & 0,37 & 0,47 & 1,5 & 0,25 \\
POCONÉ & & 69,03 & 361,77 & 4141,94 & 0,26 \\
BARÃO DE & & 2,87 & 3,72 & 17,22 & 1,35 \\
MELGAÇO & & 577,33 & 2220,63 & 53692,46 & 0,14 \\
CÁCERES & Produção & &
\end{tabular}

Fonte: INDEA (2016-2017). Elaboração: o autor

Segundo dados do INDEA (2016-2017) analisados nesta pesquisa, o município de Curvelândia não possui nenhum empreendimento de piscicultura registrado oficialmente. Já Barão de Melgaço apresenta quatro pisciculturas registradas, Cáceres apresenta 60 e Poconé apresenta 94 empreendimentos. Observa-se que os municípios de Poconé e Cáceres possuem a maior quantidade de viveiros (Figuras 5 a-d ) e lâmina d'água (Figuras 6 a-d) da Microrregião. 

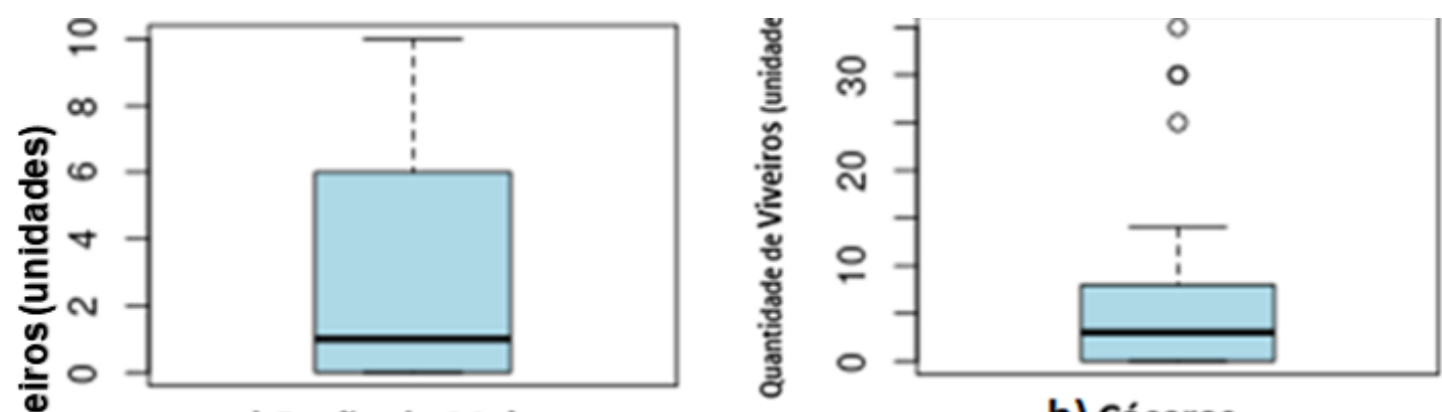

a) Barão de Melgaço

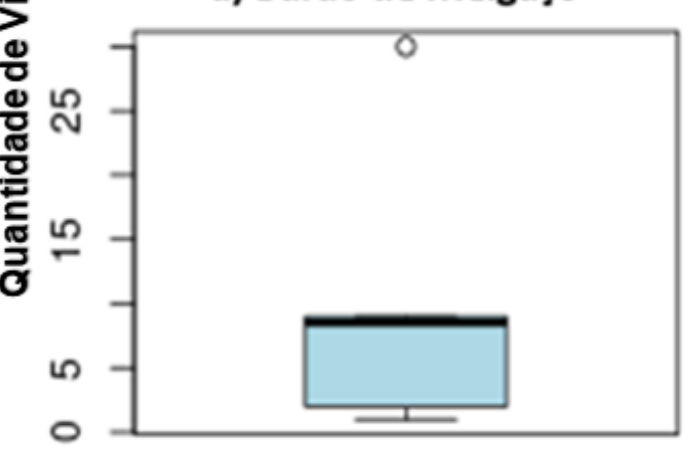

c) Curvelândia

b) Cáceres

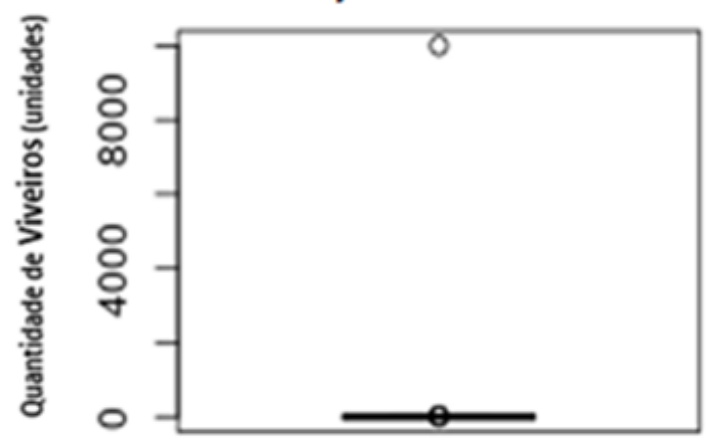

d) Poconé

Figura 5: Boxplot da quantidade de viveiros em função do município na Microrregião do Alto Pantanal. Fonte: INDEA (2016-2017) [62].

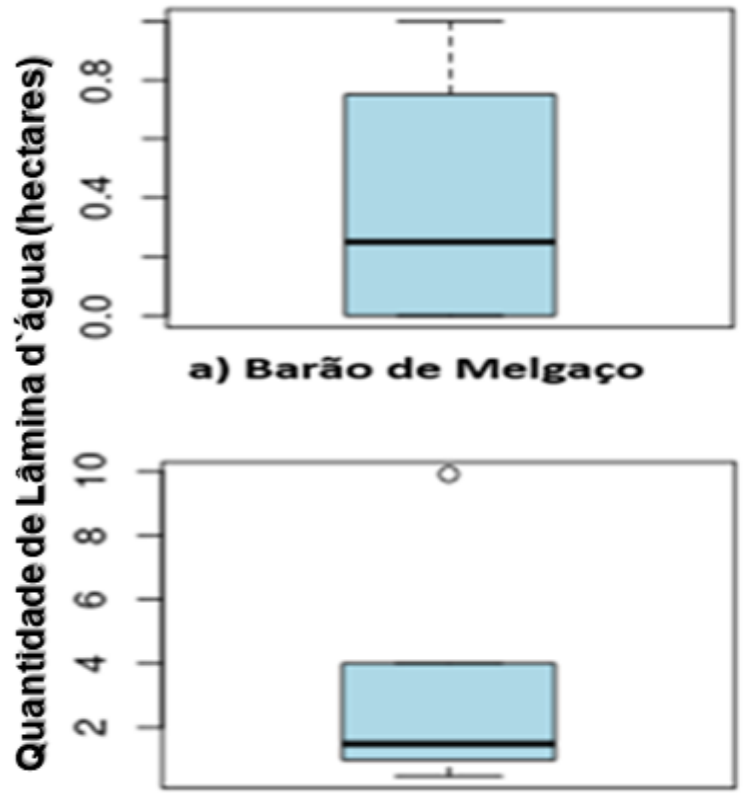

c) Curvelândia

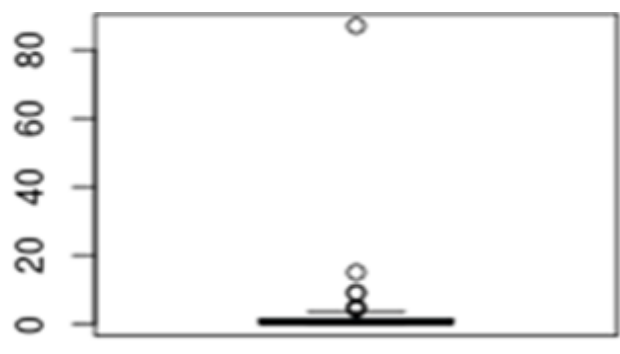

b) Cáceres

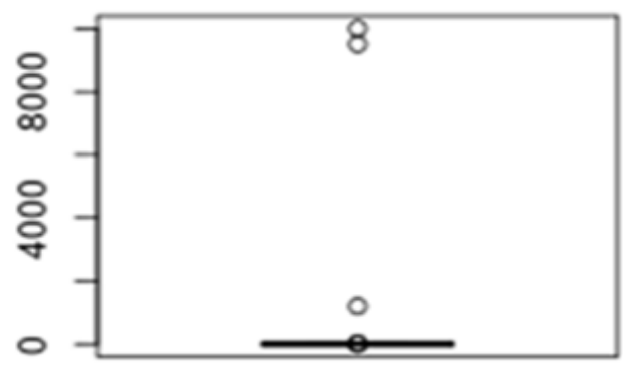

d) Poconé

Figura 6: Boxplot da quantidade de lâmina d'agua em função do município na Microrregião do Alto Pantanal. Fonte: INDEA (2016-2017) [62].

Nota-se ainda, que, em relação à produção, Poconé demonstra valores superiores aos produzidos no município de Cáceres (Figuras 7 a-d). É importante salientar que os municípios de Curvelândia e Barão de Melgaço não emitiram Guias de Transporte Animal (GTA) de acordo com os dados dos anos de 2016 e 2017, fornecidos pelo INDEA/MT. 


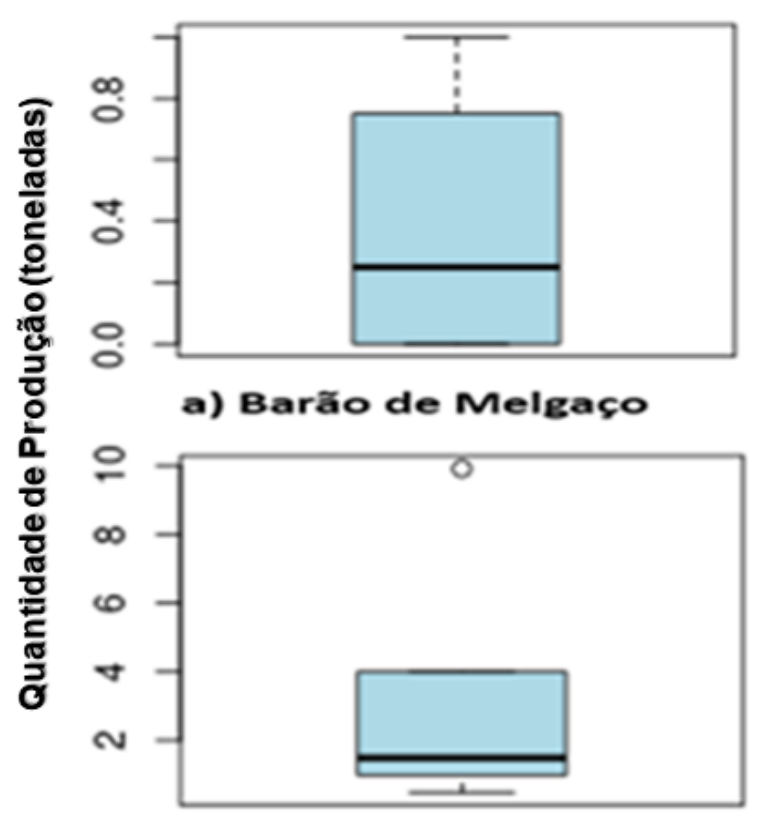

c) Curvelândia
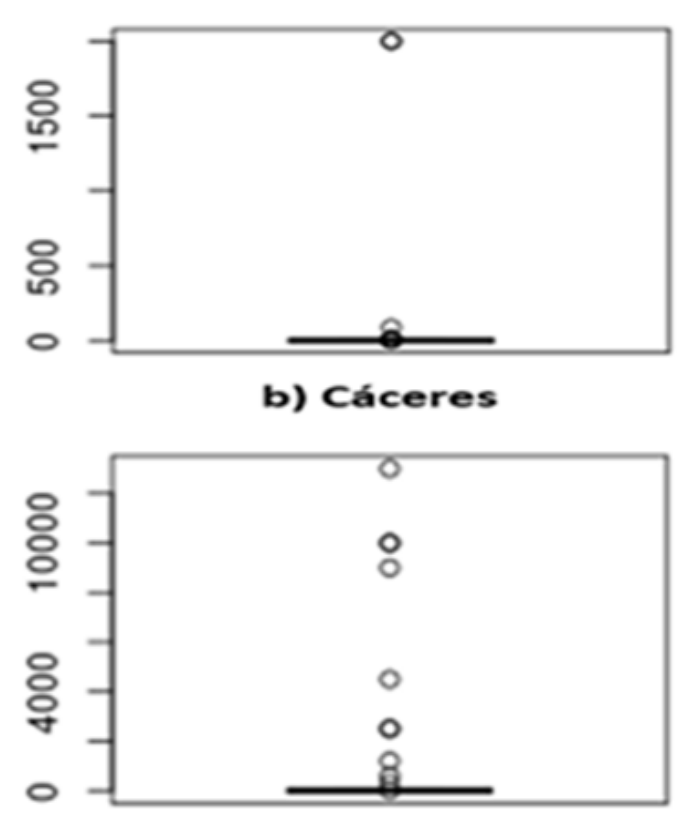

d) Poconé

Figura 7: Boxplot da quantidade de produção em função do município na Microrregião do Alto Pantanal. Fonte: INDEA (2016-2017) [62].

Visando encontrar explicações para tais fatos, foram realizadas comparações entre esses dois maiores produtores da Microrregião, Cáceres e Poconé, segundo dados do Brasil [26, 27, 28, 29]. Ambos são municípios com Produto Interno Bruto (PIB) elevado e com grande arrecadação municipal, diferente de Curvelândia e Barão de Melgaço que evidenciaram uma economia estagnada e com baixa arrecadação [26, 27].

Cáceres é o $5^{\circ}$ município de Mato Grosso mais populoso, tendo sua economia diversificada [29]. O Agronegócio de Poconé também possui uma economia diversificada muito semelhante, concentrado-se suas atividades, principalmente, na área de serviços e agropecuária [28]. Poconé apresenta um produtor que possui quantidades de viveiros, lâmina d'água e produção bem superiores aos demais municípios.

Para a quantidade de viveiros, nota-se a presença de valores outliers em todos os municípios, com exceção do Barão de Melgaço. Associado a isto, observa-se o que pode indicar a presença de dois tipos de produtores (pequenos e grandes). Observa-se na distribuição de dados que existe três municípios que possuem pisciculturas inativas e estas aparecem nos boxplots sobrepostas sobre o eixo $\mathrm{x}$, com valor 0 (zero) para todas as três variáveis. Identificou-se que o único município que não tem pisciculturas inativas Curvelândia.

Observou-se ainda nos gráficos boxplot o aparecimento de muitos outliers para as três variáveis, justificados por alguns produtores nos municípios de Cáceres, Poconé e Curvelândia. Barão de Melgaço não apresentou dados discrepantes, não apresentando outliers.

As análises dos dados através do teste de Kruskal-Wallis não indicaram diferenças entre as quantidades de pescado produzidas em relação aos municípios ( $>>0,05)$. Por outro lado, observaram-se diferenças entre os municípios em relação às demais variáveis. Em relação à quantidade de viveiros, observou-se um maior número de viveiros por produtor para os municípios de Curvelândia e Cáceres em relação ao município de Poconé. Por outro lado, em relação a quantidade de Lâmina d'água o município de Curvelândia apresenta os maiores valores, diferindo dos municípios de Poconé e Barão de Melgaço (Tabela 2). 
Tabela 2. Comparação de postos das variáveis analisadas em função dos municípios de Barão de Melgaço, Cáceres, Curvelândia e Poconé, analisadas por meio do Teste de Kruskal-Wallis, com dados do INDEA, para o período de 2016-2017.

\begin{tabular}{cccc}
\hline Município & $\begin{array}{c}\text { QUANTIDADE DE } \\
\text { VIVEIROS }\end{array}$ & LÂMINA D’ÁGUA & PRODUÇÃO \\
\hline BARÃO DE & $75,38^{\mathrm{ab}}$ & $65,88^{\mathrm{b}}$ & $67,12^{\mathrm{a}}$ \\
MELGAÇO & $91,28^{\mathrm{a}}$ & $84,72^{\mathrm{ab}}$ & $81,18^{\mathrm{a}}$ \\
CÁCERES & $123,58^{\mathrm{a}}$ & $121,67 \mathrm{a}$ & $112,58^{\mathrm{a}}$ \\
CURVELÂNDIA & $74,58^{\mathrm{b}}$ & $79,29^{\mathrm{b}}$ & $82,08^{\mathrm{a}}$ \\
\hline
\end{tabular}

Elaboração: o autor. Observação: letras iguais indicam ausência de diferença estatística entre as amostras. Fonte: INDEA/MT (2016-2017) [62].

Em relação às condições sociais dos municípios de Poconé e Barão de Melgaço, já foi constatados essas cidades estão sendo levadas para um processo de favelização, pelo mesmo processo das grandes cidades [30]. Além disso, essas localidades são acometidas por falta de planejamento urbano e políticas públicas, principalmente que venham a atender a preservação ambiental e uso dos recursos naturais e, que não há atenção as condições básicas de cuidados com as populações mais pobres, comprometendo os direitos da cidadania, dando origem as favelas [30].

Os dados publicados pelo censo agropecuário pelo Instituto Brasileiro de Geografia e Estatística demonstrou haver registros de comercialização de peixes nos municípios de Curvelândia e Barão de Melgaço no ano de 2017 [29].

Dados semelhantes foram encontrados nesta pesquisa, visto que através da estatística descritiva de vendas de peixes em cativeiros, pode-se observar a ausência de vendas nos municípios de Barão de Melgaço e Curvelândia no período avaliado, ou seja, em 2016 e 2017. Tais municípios apresentaram produção, pois não apresentam registros nas Guias de Transporte Animal (GTAs). Possivelmente esses municípios possuem pequenos viveiros escavados, destinados ao abastecimento de subsistência e ou mercado local restrito.

Constatou-se nesta investigação que o município de Poconé é o maior vendedor de peixes de cativeiro na Microrregião do Alto Pantanal, apresentando maior média nos dois anos analisados 2016 e 2017. O maior valor comercializado pelos produtores do município de Cáceres foi no ano de 2016, totalizando 175.450 toneladas e Poconé foi em 2017, com 191.000 toneladas vendidas. A soma total das vendas de ambos os municípios, nos anos de 2016 e 2017 foram iguais a 674.400 toneladas, mostrando-se minimamente superior em Poconé, com um montante de 355.650 toneladas em relação ao montante vendido em Cáceres de 318.750 toneladas. Assim, constatouse que houve de diferença nas vendas de Poconé em relação a Cáceres, sendo que Poconé vendeu 36.900 t a mais que Cáceres nos anos de 2016 e 2017 (Tabela 3). A média de vendas em Poconé foi $27.677,79 \mathrm{t}$, superior a Cáceres que foi de $9.375 \mathrm{t}$, sendo justificado porque Cáceres apresenta maior número de viveiros e produtores do que Poconé, reduzindo a média (Tabela 3).

Tabela 3 - Análise estatítica das vendas de peixes criados em cativeiro em função dos municípios na Microrregião do Alto Pantanal, de acordo com dados do INDEA, no período de 2016-2017 [62].

\begin{tabular}{ccccc}
\hline Período & Município & Média (toneladas) & Desvio Padrão & $\begin{array}{c}\text { Soma } \\
\text { (toneladas) }\end{array}$ \\
\hline \multirow{2}{*}{$\mathbf{2 0 1 6}$} & Cáceres & $9.234,21$ & $7.330,985$ & 175.450 \\
& Poconé & $23.521,43$ & $29.067,36$ & 164.650 \\
\hline \multirow{2}{*}{2017} & Cáceres & $9.553,33$ & $8.909,775$ & 143.300 \\
& Poconé & $31.833,33$ & $46.657,98$ & 191.000 \\
\hline \multirow{2}{*}{ Total } & Cáceres & 9.375 & $7.938,421$ & 318.750 \\
& Poconé & $27.677,79$ & $36.716,83$ & 355.650 \\
\hline
\end{tabular}

Elaboração: o autor. Fonte: INDEA (2016-2017) [62] 
O teste de Kruskal-Wallis não identificou diferenças ( $\mathrm{p}>0,05)$ entre os municípios para os anos de 2016, 2017 e período total (Tabela 4). Assim, os dados observados em cada município podem ser considerados pertencentes à mesma população.

Tabela 4. Teste de Kruskal-Wallis para a comparação de postos da variável quantidade de peixes analisadas em função dos municípios de Cáceres e Poconé.

\begin{tabular}{cccc}
\hline Município & $\mathbf{2 0 1 6}$ & $\mathbf{2 0 1 7}$ & Total \\
\hline Cáceres & $13,08^{\mathrm{a}}$ & $9,87^{\mathrm{a}}$ & $29,12^{\mathrm{a}}$ \\
\hline Poconé & $14,64^{\mathrm{a}}$ & $13,84^{\mathrm{a}}$ & $22,04^{\mathrm{a}}$
\end{tabular}

Valores seguidos pela mesma letra não diferem entre si teste de Kruscal-Wallis a 5\% de probabilidade Elaboração: o autor. Fonte: INDEA (2016-2017) [62].

A piscicultura também é uma oportunidade para que pequenos e médios produtores possam ingressar no mercado do agronegócio, haja vista que o investimento inicial é menor quando comparado com os outros sistemas de produção de carne animal [9]. Assim como qualquer outra atividade, a piscicultura exige acompanhamento técnico especializado para a sua implantação e o processo produtivo [3].

Sob esse viés, em Mato Grosso, foi promulgada em 16 de janeiro de 2018, a Lei no 10.669/18 que regulamenta e disciplina a piscicultura no estado. Segundo os piscicultores locais e suas classes representativas, tal promulgação terá como uma de suas principais consequências a ampliação da produção de peixes em cativeiro, visto que, para esses casos, tornou-se possível a desburocratização da regularização de novos empreendimentos, como consta em seu Artigo $4^{\circ}$ que determina:

Os piscicultores com até 5 (cinco) hectares de lâmina d'água em tanque escavado e represa ou até 10.000 (dez mil) metros cúbicos de água em tanquerede ficam dispensados de licenciamento ambiental e outorga, bem como do pagamento de taxas de registro e outorga de água, devendo, porém, preencher cadastro junto ao Órgão de Defesa Sanitária Animal do Estado [32].

Além dessa nova legislação, foi prorrogada até 2027, a isenção fiscal para pequenos e médios produtores. Esse otimismo pela categoria de produtores vem sendo objeto de críticas de ambientalistas, visto que a Lei ${ }^{\circ}$ 10.669/2018 autoriza a reprodução, criação e comercialização de peixes exóticos, como, por exemplo, da tilápia, Oreochromis niloticus.

Constatou-se que no ano de 2016 o município de Chapada dos Guimarães foi o principal responsável pelas compras de peixes da Microrregião do Alto Pantanal Mato-grossense (Figura 8). Já no ano de 2017, o principal município responsável pela compra de peixes da região foi o município de Vila Bela da Santíssima Trindade. Ao analisar o período total (01 de janeiro de 2016 a 31 de dezembro 2017), observou-se que o município de Cáceres se destacou como maior fornecedor. Quando analisado apenas a compra de peixes oriundos do município de Cáceres (Figura 8), seus maiores compradores foram os municípios de: Chapada dos Guimarães (2016) e Vila Bela da Santíssima Trindade (2017). 


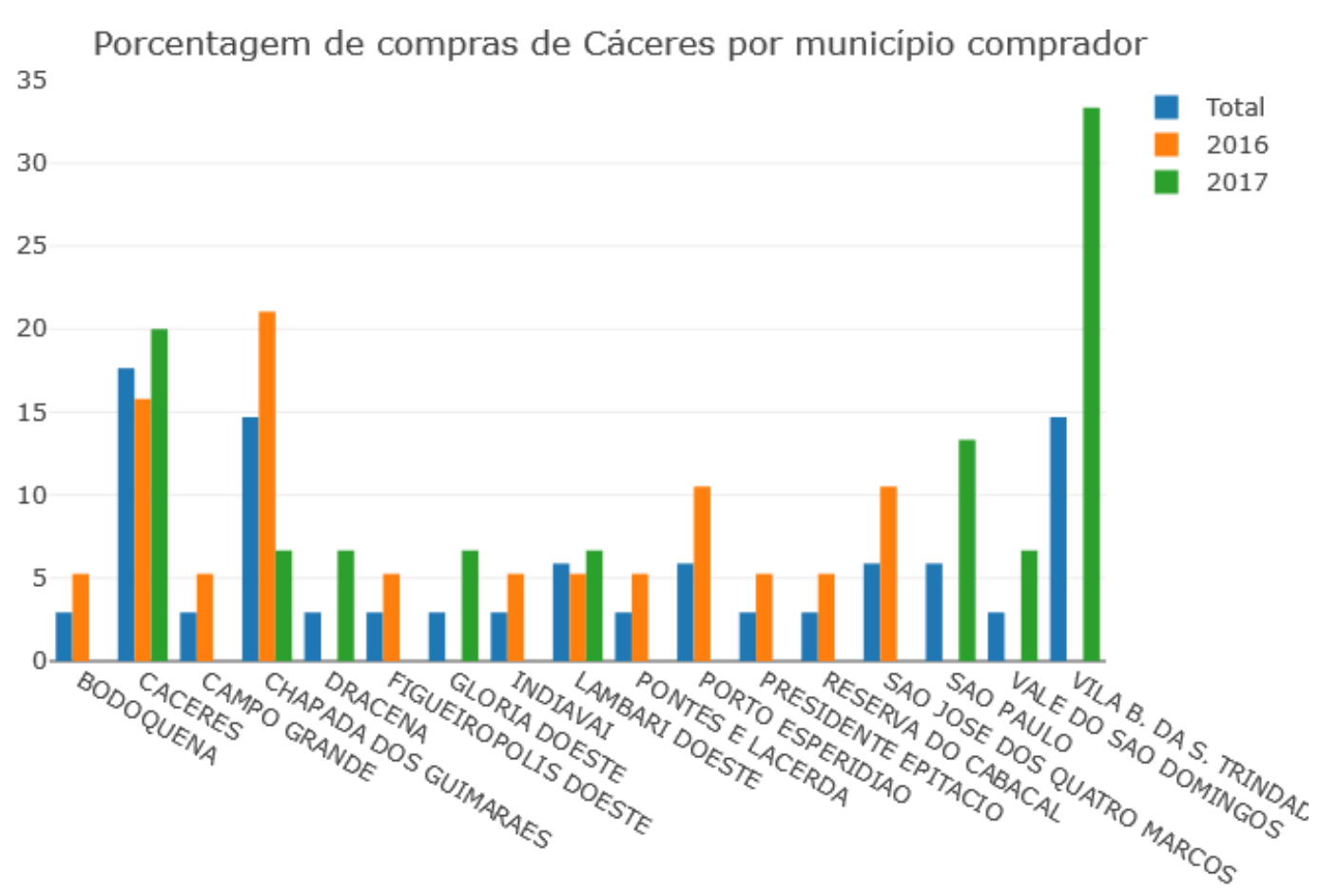

Figura 8 - Percentual de peixes comprados por municípios nos períodos avaliados (2016-2017) na Microrregião do Alto Pantanal. Fonte: Elaboração: o autor. INDEA (2016-2017) [62].

Outra análise a ser destacada em relação à venda dos peixes produzidos em cativeiro no município de Cáceres, diz respeito ao abastecimento interno do próprio município e suas vendas para municípios do mesmo estado. Dos 17 municípios que Cáceres vende peixes de cativeiro, 12 são do estado de Mato Grosso, representando 64,7\% de suas vendas. Além disso, Cáceres forneceu peixes para dois estados diferentes, Mato Grosso do Sul (municípios de Bodoquena e Campo Grande) e São Paulo (São Paulo, Dracena e Presidente Epitácio).

Paralelo a isso, o município de Poconé comercializou peixes durante os anos de 2016 e 2017 para seis municípios, sendo cinco de Mato Grosso e um do Distrito Federal (Brasília). Em ambos os casos, não foram constatadas vendas para o mercado externo.

\section{CONCLUSÃO}

A prática da piscicultura na Microrregião do Alto Pantanal foi avaliada de forma a entender e a externar suas potencialidades, visando à produção e à comercialização, mas valorizando também a perspectiva crítica do modelo do agronegócio ali praticado, no contexto de riscos e danos que podem advir dessa prática.

Constatou-se que a criação de peixes em cativeiros pode proporcionar a melhor distribuição de renda entre as populações com menor poder aquisitivo, criar maior quantidade de postos de trabalho, oportunizar o empreendedorismo, minimizar impactos ambientais negativos nos ambientes naturais e promover um manejo sustentável. Nesse aspecto, o entendimento de que a sustentabilidade de um setor produtivo torna-se relevante a inclusão social, distribuição de renda, acesso aos bens e serviços públicos e privados de qualidade, saúde, sanidade e segurança alimentar. Dessa forma, como constatado, os municípios de Curvelândia e Barão de Melgaço, pela prática da piscicultura insipiente, de baixa tecnologia e somente visa atender o mercado interno.

No que tange aos aspectos ambientais, deve-se promover melhores avaliações da inflaestruturas dos viveiros, locais de instalações, formas de manejo alimentar e de patologias, descarte de efluentes e extensão dos empreendimentos da produção. Os viveiros identificados estão sempre às margens (matas ciliares) dos rios das bacias do Cuiabá e São Loureço, os quais podem oferecer 
riscos de biopoluição acidental ou intencional, poluição dos recursos hídricos por descarga de efluentes e disseminação de doenças.

Ressaltou-se que a produção e comercialização de peixes na Microrregião do Alto Pantanal se caracterizam por se apresentarem de forma pungente e em crescimento. Observou-se, ainda, que os municípios de Cáceres e Poconé são potencialmente fortes na Microrregião do Alto Pantanal, visando a produção/comercialização de peixes criados em cativeiro (viveiros escavados), mas que requerem mais incentivo, investimentos, desenvolvimento tecnológico e educação para ampliar sua produtividade.

Os municípios da região caracterizam-se em atender ao mercado abastecedor interno importante (principalmente local e regional), mas como potencialidade de expansão, desde que rigorosamente planejada e que atenda práticas de manejo sustentáveis.

\section{AGRADECIMENTOS}

À Universidade Católica Dom Bosco (UCDB), à Coordenação de Aperfeiçoamento de Pessoal da Educação Superior (CAPES), ao Instituto Federal de Mato Grosso PROPES e Mato Grosso do Sul (IFMT e IFMS) e Instituto de Defesa Agropecuária de Mato Grosso (INDEA/MT).

\section{REFERÊNCIAS BIBLIOGRÁFICAS}

1. Santos EL, Soares OLD, Tenório EC, Soares TJ, Silva LF, Gusmão Júnior ELS. Desempenho de tambaquis (Colossoma macropomum) submetidos a restrição alimentar e a realimentação em tanquesrede. Arq Bras Med Vet Zootec. 2018;70(3):931-938. doi: 10.1590/1678-4162-989134.

2. FAO - Food And Agriculture Organization United Nation. Organização das Nações Unidas (ONU). The state of world fisheries and Aquaculture. 2018.

3. Torres SM, Pereira FDAR, Souza, CCD, Ferreira, MB. Análise da eficiência da produção da piscicultura na região de Dourados - MS. Rev Espacios. 2017;38(52).

4. Embrapa - Empresa Brasileira de Pesquisa Agropecuária. Pesca e aquicultura. Fishes and Aquaquiculture. Brazilian aquaculture grows $123 \%$ in ten years. 2016. http://twixar.me/f7D1.

5. Santos FR, Silva AM. A importância da educação ambiental para graduandos da Universidade Estadual de Goiás: Campus Morrinhos. Interações. 2017;18(2):71-86. https://bit.ly/2V1PpWa.

6. Bandeira MGA, Nascimento JS. Estudo prospectivo relativo à atividade da tilápia para a indústria de alimentos no período de 2006 a 2016. Cad Prospecção. 2017;10(3):552-562. doi:10.9771/cp.v10i3.23029

7. Famato - Federação da Agricultura e Pecuária do Estado do Mato Grosso. Diagnóstico da Piscicultura em Mato Grosso. Instituto Mato-Grossense de Economia Agropecuária (IMEA) - Cuiabá/MT. 2014.

8. Aquamat - Associação dos Aquicultores do estado de Mato Grosso. Piscicultura em expansão. Cuiabá, 2018.

9. Locks CJ, Miotyo CL, Paranhos Filho AC. Contribuição do Satélite CBERS-2, Sensor WFI, na delimitação das regiões do Pantanal brasileiro. Anais do XV Simpósio Brasileiro de Sensoriamento Remoto - SBSR, Curitiba, PR, Brasil, 30 de abril a 05 de maio de 2011, INPE p.3851.

11. Paranhos Filho AC, Moreira ES, Oliveira AKM, Pagotto TCS, Mioto CL. Análise da variação da cobertura do solo no Pantanal de 2003 a 2010 através de sensoriamento remoto. Eng Sanit Ambient. 2014;19:69-76. doi:10.1590/S1413-41522014019010000305.

12. Novais JWZ, Novais JWZ, Sanches L, Silva LBD, Machado NG, Aquino AM, Pinto Junior OB. Albedo do Solo abaixo do Dossel em Área de Vochysia divergens Pohl no Norte do Pantanal. Rev Bras Meteorol. 2016;31(2):157-166. doi:10.1590/0102-778631220150001.

13. Harris MB, Tomas W M, Mourão G, Silva CJ, Guimarães E, Sonoda F, Fachim E. Desafios para proteger o Pantanal brasileiro: ameaças e iniciativas em conservação. Megadiversidade. 2005;1(1):1565-164.

14. Junk WJ, Piedade MTF, Lourival R, Wittmann F, Kandus P, Lacerda LD, Bozelli RL, Esteves FA, Nunes da Nunha C, Maltchik L, Schöngart J, Schaeffer-Novelli Y, Agostinho AA, Nobrega RLB, Camargo E. Parte I: Definição e Classificação das Áreas Úmidas (AUs) Brasileiras: Base Científica para uma Nova Política de Proteção e Manejo Sustentável. p. 13-76. In: Nunes da Cunha C, Piedade MTF, Junk WJ (Orgs.). Classificação e Delineamento das Áreas Úmidas Brasileiras e de seus Macrohabitats. Cuiabá - MT: EdUFMT. 2015. 
15. Magalhães GC, Magalhães GC de, Fantin-Cruz I, Zeilhofer P, Dores EFGC. Metais potencialmente tóxicos em rios a montante do Pantanal Norte. Rev Ambient Água. 2016;11(4):833-850. doi:10.4136/ambi-agua.1827.

16. Pereira Júnior A, Pereira ER. Degradação ambiental e a diversidade biológica/biodiversidade: uma revisão integrativa. Enciclopédia Biosfera. Centro Cient Conhecer. 2017;14(26). doi: 10.18677/EnciBio_2017B79.

17. Ferreira ABB. Pantanal Mato-Grossense: considerações sobre a proteção constitucional para um desenvolvimento econômico sustentável. Interações. 2013;14(1):11-20. doi:10.1590/S151870122013000100002 .

18. Santos-Silva L, Golovatch SI, Pinheiro TG, Chagas-Jr A, Marques MI, Battirola LD. Myriapods (Arthropoda, Myriapoda) in the Pantanal of Poconé, Mato Grosso, Brazil. Biota Neotr. 2019;19(13). doi:10.1590/1676-0611-bn-2018-0631.

19. Alho CJR, Sabino JÁ. Conservation agenda for the Pantanal's biodiversity. Brazn J Biol. 2011;71(1)(suppl.):327-335. doi:10.1590/S1519-69842011000200012.

20. Froehlich O, Cavallaro M, Sabino J, Súarez YR, Vilela M. J. A. Checklist da ictiofauna do Estado de Mato Grosso do Sul, Brasil. Iheringia, Série Zoologia. 2017;107(supl). doi:10.1590/1678$4766 \mathrm{e} 2017151$.

21. Miranda CS, Gamarra RM, Mioto CL, Silva NM, Conceição Filho AP, Pott A. Analysis of the landscape complexity and heterogeneity of the Pantanal wetland. Braz J Biol. 2018;78(2):318-327. doi: 10.1590/1519-6984.08816.

22. Ferreira, A. B. B. Pantanal Mato-Grossense: considerações sobre a proteção constitucional para um desenvolvimento econômico sustentável. Rev Interações. 2013;14(1):11-20.

23. PEIXE BR - Associação Brasileira da Piscicultura. Anuário Peixe BR da Piscicultura. 2019. https://bit.ly/2EmKqtE.

24. Chiaravalloti RM. Pantanal, um lugar intocado? Conflitos relacionados à conservação do pantanal. Rev Ambiente \& Sociedade. 2016;19(2):305-310. doi:10.1590/1809-4422ASOC142964V1922016.

25. Brasil - Instituto Brasileiro de Geografia e Estatística (IBGE). Panorama dos Municípios - população de Curvelândia (IBGECIDADES). 2018.

26. ___ Instituto Brasileiro de Geografia e Estatística (IBGE). Panorama dos Municípios - população de Barão de Melgaço (IBGECIDADES). 2018.

27. __ - Instituto Brasileiro de Geografia e Estatística (IBGE). Panorama dos Municípios - População de Poconé (IBGECIDADES).

28. ___ Instituto Brasileiro de Geografia e Estatística (IBGE). Panorama dos Municípios - população de Cáceres (IBGECIDADES). 2018.

29. ___ Instituto Brasileiro de Geografia e Estatística (IBGE). SIDRA - Banco de tabelas estatísticas. Censo Agropecuário 2017. 2017.

30. Jorge W. Periferia e favelização avançam nas grandes cidades da América Latina. Cienc Cult. 2005;57(2):9-12.

31. Silva CJD, Silva JAF. No ritmo das águas do pantanal. NUPAUB - Núcleo de Apoio à Pesquisa sobre Populações Humanas e Áreas Úmidas Brasileiras, Universidade de São Paulo (USP), São Paulo, 1995.

32. Mato Grosso - Governo do Estado de Mato Grosso - Assembléia Legislava. Lei 10.669 de 18 de janeiro de 2018. 2018.

33. Creswell JW. Projeto de Pesquisa - Métodos qualitativo, quantitativo e misto. $2^{\text {a }}$ Edição. Tradução de Luciana de Oliveira da Rocha. Porto Alegre: Artmed, 2007. 248 p. http://twixar.me/FVD1.

34. Sampieri RH, Collado CF, Lucio M. del PB. Metodologia de Pesquisa. $5^{\mathrm{a}}$ ed. Porto Alegre: Penso, 2013, cap. 13. (AD-espanhol).

35. Souza KR, Kerbauy MTM. Abordagem quanti-qualitativa: superação da dicotomia quantitativaqualitativa na pesquisa em educação. Educação e Filosofia. 2017;31(61):m21-44. doi:10.14393/REVEDFIL.issn.0102-6801.v31n61a2017-p21a44.

36. Mattar NF. Pesquisa de marketing. 4. ed. Edição Compacta. São Paulo: Atlas, 2008.

37.Mendiburu FD. Package 'agricolae'. Statistical Procedures for Agricultural Research. http://twixar.me/ss01.

38. $\mathrm{R}$ Core Team. A Language and Environment for Statistical Computing. 2017. https://www.R-project.org/.

39. Sievert CP. Plotly 4.8.0. 2018. https://cpsievert.me/.

40. Darold FR, Irigaray CTJH. A Importância da Preservação das Áreas Úmidas como Mecanismo de Efetivação do Direito Constitucional ao Meio Ambiente Ecologicamente Equilibrado. Rev Cient Multidisc. 2018;5:198-213.

41. Schulter EP, Vieira Filho JER. Evolução da piscicultura no brasil: diagnóstico e desenvolvimento da cadeia produtiva de tilápia. 2017. Instituto de Pesquisa Econômica Aplicada (IPEA). 
42. Amâncio ALDL, Silva Neto MRda, Jordão Filho J, Fonseca SBda, Silva JHVD. Dietary protein requirements for tambaqui Colossoma macropomum (Cuvier, 1818) juvenile. Rev Ciênc Agron. 2019;50(2):259-266. doi:10.5935/1806-6690.20190030.

43. Paula FG. Desempenho do tambaqui (Colossoma macropomum), da pirapitinga (Piaractus brachypomum) e do híbrido tambatinga (C. macropomum X P. brachypomum) mantidos em viveiros fertilizados na fase de engorda. Dissertação (Mestrado em Veterinária). Programa de Pós-graduação em Veterinária. Escola de Veterinária, Universidade Federal de Goiás. Goiânia (GO), 2009.

44. Cruz AG, Melo AEFD, Sobreira CB, Mazeto MD, Naoe LK. Densidade x Custo de Ração: piscicultura. Palmas: Seagro-TO / Unitins, p. 13. Seagro Bol Técnico. 2006;(3).

45. Rodrigues APO, Silva APD, Maciel PO, Pedroza Filho MX. Piscicultura familiar em regiões de déficit hídrico. Circular Técnica 2, Embrapa de Palmas (TO), 2015.

46. Romagosa E, Paiva PDE, Andrade-Talmelli EFD, Godinho HME. Biologia reprodutiva de fêmeas de cachara, Pseudoplatystoma fasciatum (TELEOSTEI, SILURIFORMES, PIMELODIDAE), mantidas em cativeiro. Bol Inst Pesca. 2003;29(2):151-159.

47. Kubitza F, Ono EA, Campos JL. Alguns Destaques da Piscicultura em 2011. Revista Panorama da Aquicultura. 2011;21(128):14-23. 2011.

48. Sabaini DDS, Casagrande LP, Barros AFD. Viabilidade econômica da criação do pintado da amazônia (Pseudoplatystoma sp.) em tanques-rede no estado de Rondônia, Brasil. Bol Inst Pesca. 2015;41(4):825835.

49. Almeida Filho RL, Honorato CA, Almeida LC, Ushizima TT, Santa Maria FM. Nutrição de surubim (Pseudoplatystoma ssp.) - Desafio para Aquicultura. Rev Eletr Nutritime. 2012;9:1995-2010.

50. Rotta MA, Gonda MF. "Ictioproveta" para a biometria indireta do peso de surubins (pintado e cachara) utilizando seu volume e densidade. Comunicado técnico 42. EMBRAPA, Corumbá (MS). 2004. https://www.infoteca.cnptia.embrapa.br/infoteca/bitstream/doc/812035/1/COT42.pdf.

51. Pesca e aquicultura. Palmas: Embrapa, 2017.

52. Souza RCCL de, Calazans SH, Silva EP. Impacto das espécies invasoras no ambiente aquático. Ci Cult. 2019;61(1):35-41.

53. IUCN - (International Union for Conservation of Nature). 100 de las Especies Exóticas Invasoras más dañinas del mundo. 2017.

54. Fine PVA. The invasibility of tropical forests by exotic plants. J Trop Ecol. 2002;18(5):687-705. doi:10.1017/S0266467402002456.

55. Nascimento FL, Catella AC, Moraes AS. Distribuição especial do tucunaré; Cichla sp. (Pisces, Cichlidae), peixe amazônico introduzido no Pantanal, Brasil. Boletim de Pesquisa e Desenvolvimento 24. Embrapa, 2001.

56. Ferraz de Lima JA. Recursos Pesqueiros em ambientes inundáveis (rio Cuiabá: Pantanal de Mato Grosso). Anais ... Encontro Brasileiro de Ictiologia. 1993. Palestra [s.1.]: Sociedade Brasileira de Ictiologia. Universidade de São Paulo. 1993.

57. Marques DCS, Resende, EK de. Distribuição do Tucunaré Cichla cf. monoculus (Osteichthyes, Ciclidae) no Pantanal. Boletim de Pesquisa e Desenvolvimento. Corumbá (MS): Embrapa Pantanal, 2005;61: 1-24. https://www.infoteca.cnptia.embrapa.br/bitstream/doc/812032/1/BP60.pdf

58. Araújo-Lima CARM, Gomes LC. Tambaqui (Colossoma macropomum). In: Baldisserotto B, Gomes LC. Espécies nativas para piscicultura no Brasil. Santa Maria: UFSM, 2010:175-04.

59. Silva JJD, Pires WLR, Silva JGD, Ferreira e Souza D, Moi PCP. Avaliação do custo de produção da piscicultura no assentamento Nossa Senhora Aparecida, em Várzea Grande-MT. Rev Adm Negócios Amazônia. 2016;8(1). doi:10.18361/2176-8366/rara.v8n1p39-53.

60. Pimentel D, McNair S, Janecka J, Wightman J, Simmonds C, O’Connell C, Wong E, Russel L, Zern J, Aquino T, Tsomondo T. Economic and environmental threats of alien plant, animal, and microbe invasions. Agric Ecosyst Environ. 2001;84(1):1-20. doi:10.1016/S0167-8809(00)00178-X .

61. Rossetto OC, Brasil Junior ACP. Cultura e desenvolvimento sustentável no pantanal mato-grossense: entre a tradição e a modernidade. Sociedade e Estado. 2003;18(1-2):155-175. doi:10.1590/S010269922003000100009

62. INDEA (Instituto de Defesa Agropecuária de Mato Grosso). Cadastro Atualizado de Piscicultores, Guias de Transporte Animal (GTA) e Relatório de Despesca do estado de Mato Grosso. 2016-2017. 